\title{
Arizona Averages Over 25 Opioid Overdoses Per Day
}

An Arizona Republic article and the Arizona Department of Health Services Director's blog, Dr. Cara Christ, brings the opioid crisis home $(1,2)$. Christ states that over 3200 opioid overdoses with over 400 deaths occurred between June 15 and October 17 in Arizona. This averages to over 25 overdoses and 3 deaths per day.

Some of the data from Christ's blog are below:

- Males 25-29 have the highest rates of suspected opioid overdoses.

- $37 \%$ of people experiencing a suspected opioid overdose had an opioid prescription in the two months prior to their overdose.

- The majority of overdoses occur at home.

- The most commonly cited pre-existing health conditions of those with suspected overdoses was chronic pain. Depression and other behavioral health conditions were also common health conditions noted.

- Meth and heroin were the most frequently cited drugs involved in reported neonatal abstinence syndrome.

- About $40 \%$ of people experiencing suspected opioid overdoses who had a prescription in the Controlled Substances Prescription Monitoring Program had been prescribed both benzodiazepines and opioids in 2017. When these medications are combined, it is so dangerous that the FDA gives it a "black box" warning.

- About $40 \%$ of people experiencing a suspected overdose that had prescription history in the Controlled Substances Prescription Monitoring Program (CSPMP) had received opioid prescriptions from 10 or more providers.

- Only about $25 \%$ of clinicians prescribing controlled substances checked the CSPMP prior to prescribing.

On October 16, a new mandate went into effect that requires clinicians to check the CSPMP prior to prescribing an opioid or benzodiazepine. Other states implementing such mandates have experienced reductions in people with 4 or more prescribers or pharmacies, reductions in opioid prescribing, and reductions in Morphine Milligram Equivalent daily doses.

The CSPMP requires registration and login but is relatively easy to use (3). You can search not only in Arizona but other states as well. Personally, as a pulmonary consultant I infrequently prescribe opioids or benzodiazepines. However, I have used the website once to check a benzodiazepam prescription for a patient I suspect might be addicted. No other prescriptions were found. It at least gave me some assurance that he was not obtaining prescriptions from multiple practioners while we attempt to wean him off this medication. 
Richard A. Robbins, MD

Editor, SWJPCC

\section{References}

1. McCrory C. More than 400 opioid-overdose deaths reported in Arizona since June 15. Arizona Republic. October 27, 2017. Available at: http://www.azcentral.com/story/news/local/arizona/2017/10/27/more-than400-opioid-overdose-deaths-reported-arizona-since-june-15/809157001/ (accessed 10/28/17).

2. Christ CM. Opioid update: latest data and emergency rules update. October 17, 2017. Available at: http://directorsblog.health.azdhs.gov/opioid-updatelatest-data-and-emergency-rules-update/ (accessed 10/28/17).

3. Arizona Board of Pharmacy. Arizona PMP Aware. Available at: https://pharmacypmp.az.gov/ (accessed 10/28/17). 